Pathophysiology Haemostasis and Thrombosis

\title{
Coagulation Factors and Tumor Cell Biology: The Role of Tissue Factor
}

\author{
Maria Benedetta Donati ${ }^{1}$ Roberto Lorenzet ${ }^{2}$ \\ ${ }^{1}$ Center for High Technology Research and Education in Biomedical Sciences, Catholic University, Campobasso, \\ ${ }^{2}$ 'Antonio Taticchi' Unit for Atherosclerosis and Thrombosis, Istituto Ricerche Farmacologiche Mario Negri, Consorzio Mario Negri Sud, \\ S. Maria Imbaro, Italy
}

\section{Background}

Tumor cell interactions with the clotting system has been so far evaluated from two viewpoints and with a dual meaning: on one hand, significant hemostatic abnormalities and thrombotic and hemorrhagic complications have been observed in cancer patients; hemostatic complications are indeed a common cause of death in cancer patients; among the underlying mechanisms, many tumor cells possess strong procoagulant activities that promote the local activation of the coagulation system; on the other hand, tumormediated activation of the coagulation cascade has been implicated in both the formation of tumor stroma and the promotion of hematogenous metastases. Most solid tumors contain fibrin/ogen-derived material, which is important in the formation of tumor stroma, since fibrin matrices promote the migration of several cell types (transformed cells, macrophages, fibroblasts). Moreover, in hematogenous metastasis, activation of the coagulation system has been implicated, since, following entry into the circulation, tumor cells must be arrested in the microvasculature of a target organ prior to metastasis growth. The formation of platelet/fibrin/tumor cell aggregates may be causally related to endothelial adhesion and metastatic potential; from studies in experimental models, it can be concluded that, whatever modality is applied to reduce the clotting potential of the host (acting on fibrinogen itself, or blocking thrombin generation or platelet activation) intravenously injected tumor cells will be kept longer in the circulation and will then be better susceptible to destruction by the reticulo-endothelial system. In this brief survey we shall focus on the role of the coagulation system in tumor metastases with special emphasis on a pivotal system of clotting activation, the Tissue Factor/Factor VII complex.

\section{Blood Clotting, Cancer Procoagulants and Tumor Metastasis}

Tissue factor (TF), a 47-kD membrane glycoprotein tightly associated with phospholipids, is the in vivo trigger of blood coagulation pathway. The TF molecule consists of three domains: an intracellular region, a transmembrane domain, and an extracellular domain, which, following binding of coagulation factor VII and its active form VIIa, activates factors IX and X, leading to fibrin formation. Immunohistochemical studies have localized TF at tissue barriers between the body and the environment, in a pattern consistent with a 'hemostatic envelope' role of TF, whose duty is to minimize blood loss following vessel damage. Monocytes and endothelial cells, which under normal conditions do not express TF, upon appropriate stimulation,

\begin{tabular}{ll}
\hline KARGER & (c) 2003 S. Karger AG, Basel \\
Fax +41613061234 & 1424-8832/03/0337-0022\$19.50/0 \\
$\begin{array}{l}\text { E-Mail karger@karger.ch } \\
\text { www.karger.com }\end{array}$ & $\begin{array}{l}\text { Accessible online at: } \\
\text { www.karger.com/journals/pht }\end{array}$
\end{tabular}

Maria Benedetta Donati, MD, PhD

Center for High Technology Research and

Education in Biomedical Sciences

Catholic University

Loc. Tappino, 86100 Campobasso (Italy)

Tel. +390874 312278, Fax +390874312730

E-Maildonatimb@yahoo.it 
can be induced to synthesize and express it on their membranes. TF gene expression is regulated mainly at the level of transcription. When monocytes and endothelial cells are exposed to LPS or inflammatory cytokines, c-Rel/p65 heterodimers, components of the NF- $\mathrm{KB}$ transacting factor family, which are retained in the cytoplasm by the binding of the inhibitor $\mathrm{I} \kappa \mathrm{B} \alpha$, migrate to the nucleus where they bind to the $\mathrm{\kappa B}$ site in the TF promoter inducing TF gene transcriptional activation. At variance with endothelial cells and monocytes, tumor cells express intrinsic procoagulant properties without the need of exposure to any inducing agent. The main procoagulant activity of a wide variety of tumor cells has been ascribed to TF associated to cell membranes. In addition to tumor cells, TF may be also expressed in malignancy by tumor infiltrating and circulating monocytes. Studies in malignant tumors have also shown that some experimental and human tumor cells may express cancer procoagulant (CP), a cystein proteinase with direct factor $\mathrm{X}$ activating activity. $\mathrm{CP}$ is confined to the malignant phenotype and, in murine tumors, is associated with the metastatic potential of tumor cells. CP appears to be a novel vitamin $\mathrm{K}$ dependent activity, since, both in murine and in human tumors, it is depressed by treatment with warfarin or vitamin $\mathrm{K}$-deficient diet. Increased CP levels have been reported in different types of advanced solid tumors and in acute promyelocytic leukemia, where they correlate with the stage of the disease and the response to chemotherapy.

On the other hand, evidence for a role of TF in the metastatic process has repeatedly been proposed. Constitutive TF expression is reported as a characteristic feature of numerous malignant tumors, among which human colorectal carcinoma cell lines, hepatic metastasis in human colorectal carcinoma, cells from non-small-cell lung cancer patients, and highly metastatic human melanoma cells. In addition, in breast cancer, expression of TF in tumor stroma correlates with progression to invasive cancer, and tumor TF expression was proposed as an independent prognostic indicator for overall survival. Similarly, expression of TF in glioma cell lines and glioma surgical specimens correlates with the histologic grade of malignancy. Finally, transfection of TF-expressing vector in a human pancreatic adenocarcinoma cell line enhanced in vitro invasion and primary tumor growth in immunodeficient mice.

\section{Mechanisms of Tumor Metastasis Modulation by Tissue Factor}

A selective inhibition of the procoagulant activity of TF by treatment of severe combined immunodeficient (SCID) mice with anti-TF monoclonal antibodies abolished prolonged adherence of metastatic melanoma cells in the vasculature and inhibited pulmonary metastasis. Similarly, blocking the coagulation pathway at the level of TF, FXa, or thrombin, inhibited hematogenous M24met metastasis in SCID mice, and a specific thrombin inhibitor reduced murine melanoma experimental metastasis, suggesting a role for one or more products of the coagulation cascade in the metastatic process. In addition, an emerging role for TF pathway inhibitor (TFPI) as an antimetastatic agent is presently discussed. More in general, metastasis inhibition by anticoagulant treatments stresses the importance of clotting activation in the invasive process. The influence of TF on the metastatic process may however be more complex. SCID mice injected with human melanoma cells transfected with an extracellular TF mutant, in which the TF procoagulant activity was downregulated, developed metastasis, indicating that products of the coagulation pathway were not involved in the metastatic effect of TF. In a similar experimental model it was demonstrated that TF supports metastasis by both undefined functions of the cytoplasmic domain and the proteolytic activity of the TF:VIIa complex. In a similar way, using site specific mutagenesis, it was shown that, for the full metastatic effect of $\mathrm{TF}$, phosphorylation of the cytoplasmic domain and formation of a complex with FVIIa by the extracellular domain are required. Ott et al. identified an intracellular protein, actin-binding protein 280 (filamin 1), as ligand for the TF cytoplasmic domain. The interaction with filamin 1 , a cytoskeletal component, was enhanced by a Ser to ASP substitution, which mimics phosphorylation, in the TF domain, and abolished with Ala mutations, reducing cell spreading. These findings provide a molecular pathway in which, through alterations in the tumor cell cytoskeleton, the TF cytoplasmic domain supports cell migration and adhesion.

On the other hand, angiogenesis is a multifactorial process of de novo vessel formation required for invasive tumor growth and metastasis. A markedly defective vessel formation of yolk sac vessels in TF knockout mouse embryos followed by massive hemorrhaging of embryonic blood suggests a role for $\mathrm{TF}$ in fetal angiogenesis. Abnormal vascular development in the yolk sac of TF null mouse embryos could be rescued by human TF lacking the cytoplasmic domain, suggesting that embryogenesis requires the extracellular protease activity of the TF:VIIa complex. Meth-A sarcoma cells overexpressing TF grew more rapidly and formed larger and more vascularized tumors than control cells in vivo, enhancing transcription of vascular endothelium cell growth factor (VEGF), and 
diminishing transcription of the antiangiogenic molecule thrombospondin 2. Anticoagulation of the experimental animals suggested that coagulation was not involved. A positive correlation for angiogenesis and levels of TF expression was found in human prostate carcinoma and in non-small-cell lung carcinoma. TF and VEGF were found to colocalize in human tumor cells from patients with breast, lung cancer and non-small-cell lung carcinoma. A significant correlation between TF and VEGF in 13 human malignant melanoma cell lines, in which the TF cytoplasmic domain was the one playing a role, was reported. Different findings, showing that VEGF synthesis in TF expressing human lung fibroblasts was mostly dependent on the proteolytic activity of the TF:VIIa complex, were also reported. From different pieces of evidence, it can be concluded that the effects of TF expression on angiogenetic processes may further contribute to the complex TF modulation of tumor metastasis.

\section{Summary and Conclusions}

Both intravascular and cell-mediated activation of clotting promote cancer metastasis formation and growth, as documented in experimental models and some clinical studies. Tumor cell procoagulant activities have been extensively investigated in this context. The expression of tissue factor, the principal cellular activator of the coagulation cascade, can be considered a hallmark of cancer progression. The procoagulant functions of TF that lead to thrombin generation are critically important to support metastasis, in part through the generation of fibrin, that allows prolonged arrest of tumor cells in target organs. In addition, the coagulation initiation complex, i.e. TF:VIIa, generates autocrine cell signaling through protease activated receptors. A cooperation of the TF cytoplasmic domain with protease signaling may explain the different contributions of TF to metastasis and angiogenesis.

\section{Acknowledgments}

Part of the Authors' work reviewed in this survey was supported by Italian Ministry of Health (ICS 120.4/RF99.11, ISS Convenzione $\mathrm{N}: 1 \mathrm{AI} / \mathrm{F} 3)$.

\section{References}

Abe K, Shoji M, Chen J, Bierhaus A, Danave I, Micko C, Casper K, Dillehay DL, Nawroth PP, Rickles FR: Regulation of vascular endothelial growth factor production and angiogenesis by the cytoplasmic tail of tissue factor. Proc Natl Acad Sci USA 1999;96:8663-8668.

Bromberg ME, Sundaram R, Homer RJ, Garen A, Konigsberg WH: Role of tissue factor in metastasis: Functions of the cytoplasmic and extracellular domains of the molecule. Thromb Haemost 1999;82:88-92.

Callander NS, Varki N, Rao LV: Immunohistochemical identification of tissue factor in solid tumors. Cancer 1992;70:1194-1201.

Carmeliet P, Mackman N, Moons L, Luther T, Gressens P, Van Vlaenderen I, Demunck H, Kasper M, Breier G, Evrard P, Muller M, Risau W, Edgington T, Collen D: Role of tissue factor in embryonic blood vessel development. Nature 1996;383:73-75.

Contrino J, Hair G, Kreutzer DL, Rickles FR: In situ detection of tissue factor in vascular endothelial cells: Correlation with the malignant phenotype of human breast disease. Nat Med 1996;2:209-215.
Donati MB: Cancer and thrombosis: From Phlegmasia alba dolens to transgenic mice. Thromb Haemost 1995;74:278-281.

Donati MB, Evangelista V: Platelets and tumor; in Gresele P, Page CP, Fuster V, Vermylen J (eds): Platelets in Thrombotic and Non-Thrombotic Disorders. Cambridge, Cambridge University Press, 2002, pp 824-836.

Donati MB, Falanga A: Pathogenetic mechanisms of thrombosis in malignancy. Acta Haematol 2001; 106:18-24.

Donati MB, Gambacorti Passerini C, Casali B, Falanga A, Vannotti P, Fossati G, Semeraro N, Gordon SG: Cancer procoagulant in human tumor cells: Evidence from melanoma patients. Cancer Res 1986;46:6471-6474.

Falanga A, Alessio MG, Donati MB, Barbui T: A new procoagulant in acute leukemia. Blood 1988;71:870-875.

Fernandez PM, Rickles FR: Tissue factor and angiogenesis in cancer. Hematol 2002;9:101-106.

Lorenzet R, Donati MB: Blood clotting activation, angiogenesis and tumor metastasis: Any role for TFPI? Thromb Haemost 2002;87: 928-929.
Lorenzet R, Napoleone E, Celi A, Pellegrini G, Di Santo A: Cell-cell interaction and tissue factor expression. Blood Coagul Fibrinolysis 1998; 9(suppl 1):S49-S59.

Lorenzet R, Peri G, Locati D, Allavena P, Colucci M, Semeraro N, Mantovani A, Donati MB: Generation of procoagulant activity by mononuclear phagocytes: A possible mechanism contributing to blood clotting activation within malignant tissues. Blood 1983;62: 271-273.

Morgan D, Edwards RL, Rickles FR: Monocyte procoagulant activity as a peripheral marker of clotting activation in cancer patients. Haemostasis 1988;18:55-65.

Mueller BM, Ruf W: Requirement for binding of catalytically active factor VIIa in tissue factordependent experimental metastasis. J Clin Invest 1998;101:1372-1378.

Nemerson Y: Tissue factor and hemostasis. Blood 1988;71:1-8. 
Oeth P, Parry GCN, Mackman N: Regulation of the tissue factor gene in human monocytic cells: Role of AP-1, NF-кB/Rel, and Sp1 proteins in uninduced and lipopolysaccharide-induced expression. Arterioscler Thromb Vasc Biol 1997;17:365-374.

Prydz H, Camerer E, Rottingen JA, Wiiger MT, Gjernes E: Cellular consequences of the initiation of blood coagulation. Thromb Haemost 1999;82: 183-192.
Roncaglioni MC, D'Alessandro AP, Casali B, Vermeer C, Donati MB: Gamma-glutamyl carboxylase activity in experimental tumor tissues: A biochemical basis for vitamin $\mathrm{K}$ dependence of cancer procoagulant. Haemostasis 1986;16: 295-299.

Semeraro N, Colucci M: Tissue factor in health and disease. Thromb Haemost 1997;78:759-764.
Zhang Y, Deng Y, Luther T, Muller M, Ziegler R, Waldherr R, Stern DM, Nawroth PP: Tissue factor controls the balance of angiogenic and antiangiogenic properties of tumor cells in mice. J Clin Invest 1994;94:1320-1327. 